\title{
Can Marcel's Hope in Mystery Really Get Us to a Non-anthropocentric Relation to Non-human Nature in Environmental Education?
}

\author{
Clarence W. Joldersma
}

Calvin College

Oded Zipory's essay addresses the question: What sort of hope should environmental education try to inspire in their students with respect to our environmental crisis? He suggests that the hope exemplified in such education typically centers on commitments to resolving identified problems. He is critical of the sort of hope that believes technical fixes will solve the crisis, that problem solving will be sufficient. This teaches students that environmental issues are resource management problems, and that nature is a set of resources. But, he argues, this "technical hope" remains mired in a problematic anthropocentric relation to the non-human. Not only is it not sufficient, it leads to a variety of problems: "wishful thinking, naïve optimism, passive acceptance of social-environmental reality, and perhaps even despair." Although technical fixes might result in naïve optimism, my personal experience echoes felt despair as the dominant affect. Zipory suggests that to counter despair, we need a hope that is "immune to disappointment and apathy." He appeals to Marcel's idea of hope in mystery as a genuine hope that can develop in students a resistance to despair and a non-anthropocentric relation to nature. Although I'm sympathetic with the project, I have some questions about how, or whether, Marcel gets us there all the way. I will intertwine the question of anthropocentrism with that of overcoming despair, through an exploration of Zipory's three characteristics of Marcel's genuine hope. I will start with the third, then move to the first and second.

Zipory's third characteristic of Marcel's genuine hope is the inability to imagine future prospects, something Zipory suggests resists disappointment and despair by drawing from a vision yet to be unveiled. In my experience as an environmental education teacher, students have a strong temptation to 
despair, experiencing the daunting environmental problems as unfixable and feeling trapped in a set of dynamics over which they have no control. Marcel suggests that despair is linked to a certain experience of time: "Despair is in a certain sense the consciousness of time as closed, or more exactly still, of time as a prison — whilst hope appears as piercing through time." ${ }^{1}$ When students are tempted to despair, they are tempted to feel time as closed and determined, and thus feel imprisoned within its deterministic dynamics. Their envisioned solutions to the intractable problems seem inadequate. Zipory remarks that only genuine hope, hope in the power of a vision yet to be unveiled, will overcome this temptation. This means that time's seeming closedness and determinism must be broken open by something incoming, which has the ability to pierce through the walls of this temporal prison. This is the job of genuine hope. Genuine hope can be thought of as an incoming arrow that pierces our prison-like time, coming from outside of our felt determinism.

Zipory describes Marcel's first characteristic of genuine hope as patient and effortless, waiting for events to unfold in their own time rather than forcing them. It doesn't have the impatience of desires to be fulfilled, or goals to be realized. Zipory interprets impatience as efforts “intended to force one's personal rhythm on the rhythm of events beyond his reach," for example, the impatience of a human agent managing natural resources. By patience with the rhythms of the non-human, Zipory means to indicate a less anthropocentric relation to nature.

But predominantly, rather than rhythms of impersonal events (nature's rhythms), Marcel means something interpersonal, a patience with another person's rhythm of life. Marcel formulates this patience as "I place my hope in you." 2 This formulation makes clear that genuine hope is not a hope that, what Zipory calls technical hope, but a hope in. Patience can emerge because "hope in" brackets the determinism and control of the technical "hope that." But, for Marcel the "in you" signifies that a second-person relation is necessary for genuine hope to pierce the hope-that, perhaps just another human — neighbor, friend, teacher, lover. Marcel's formulation suggests that one cannot transcend the felt determinism of the present time on one's own, but requires something incoming from the outside, from a "hope in you." In this, he is like both Buber and Levinas, with 
whom his ideas have affinities. But, like them, Marcel's second-person formulation seems not to get us directly to non-buman nature in its natural resurgence. Marcel doesn't put nature in the second-person position, although it does appear in the form of non-objective participation, akin to my relation to my body.

Marcel develops this "in you" further. Genuine hope that resists the temptation to despair is ultimately "a response of the creature to the infinite Being to whom it is conscious of owing everything that it has ...." Thus, at a more fundamental level, the second-person "you" is an "infinite Being," and the "you" becomes an "absolute Thou." The move to an "I-Thou" relation with an absolute being seems to have left both nature and the realm of empirical human relations. Rather than to nature in its resurgence, Marcel's formulation "my hope in you" is thus an "appeal to the existence of a certain creative power in the world," an infinite Being. This is ultimately the "absolute Thou" that has the ability to pierce the determinism of time as a prison, an opening-up force that technical hope doesn't know. It is thus a "hope in thee" that allows hope to be patient. Patience arises through "hope in thee" by allowing total abandonment of oneself with absolute confidence, which allows the impatience associated with hope in problem solving to be transcended. This is "absolute hope ... transcending all laying down of conditions ...." . On this account, for environmental education to become patient it would need to place its hope in an infinite Being, an absolute Thou with certain creative power that might pierce the impatience of problem solving. This is not the patience gained from nature's rhythms. It is difficult to see how Marcel's idea of patience gets us to Zipory's desired non-anthropocentric relation with non-human nature.

Marcel's second characteristic of genuine hope, Zipory argues, involves "communion of self with non-self." He interprets Marcel's "non-self" in part as the "non-human," where in our communion with nature it will be experienced as a self-arising mystery, as a "natural resurgence" rather than a "natural resource." The communion dimension of "hope in mystery" thus names, Zipory intimates, a non-anthropocentric relationship with nature. But this move might also be too quick. Marcel's full formulation of genuine hope is, "I hope in thee for us." In adding "for us" to the phrase, Marcel adds the quality of 
communion. Or, communion comes in the form of "I hope in thee for us," where the absolute Thou that pierces the determinism of time also bring us together. "For $u s$ " indicates participation with others: rather than merely for myself as a singular individual, for us means intra-personal (myself with myself), inter-personal (myself with others), or inter-societal (our society with other societies). By adding "for us," the "in thee" formulation of hope plays a role beyond just piercing time's closedness by serving as a glue, binding myself to myself, myself to others, and our society to other societies. As Marcel puts it, the "absolute Thou" (capital T) is "the very cement which binds the whole into one." "An unconditional hope in the absolute Thou opens up a communion with others by cementing us together. The communion between self and non-self has landed us once more in a relation with an absolute Thou, a second-person infinite Being. Zipory rightly says that communion of self and non-self, where the latter is non-human nature, is important for environmental science. The binding of the "whole into one" in Marcel is silent the relation to non-human nature. The communion in each case is a communion of humans. So, how might a relation to the non-human become an us? It isn't clear. Marcel's characteristic of communion, central to genuine hope, doesn't yet get humans to a non-anthropocentric relation with non-human nature and the environment.

Zipory is right to intimate that hope in mystery is not merely a natural disposition, something we might attribute to technical hope, hope in our own power to see and solve environmental problems. Marcel suggests genuine hope is acquired as "a pure grace, and in the final analysis the result of supernatural help," a gift of grace coming as "a call to which we have to make a response." We might thus say with Zipory that hope in mystery is a call breaking into environmental education's prison of time, outside of its vision, that for Marcel, genuine hope calls environmental science students and teachers to respond beyond despair. But not to nature. Instead, from beyond our vision to someone Absolute. Although Marcel's hope in mystery can help students resist despair, it hasn't yet arrived at a non-anthropocentric relation to nature. 
1 Gabriel Marcel, Homo Viator; Introduction to a Metaphysic of Hope, trans.

Emma Craufurd (Chicago: H. Regnery Co., 1951), 53.

2 Ibid., 41.

3 Ibid., 47.

4 Ibid.

5 Ibid., 46.

6 Ibid., 60.

7 Ibid., 60-61.

8 Ibid., 62.

9 Ibid., 63. 